\title{
Exploring Factors Affecting Performance in Biology 5090 at Selected High Schools in Lesotho
}

\author{
Mamalanga C Lebata \\ Awelani V Mudau \\ Department of Science and Technology Education, \\ University of South Africa, South Africa \\ mudauav@unisa.ac.za
}

\section{Doi:10.5901/mjss.2014.v5n8p271}

\section{Abstract}

The performance in Biology 5090 in Lesotho high schools has been poor and the purpose of this study was to identify factors responsible for the poor performance. The study also identified ways in which teachers envisage to improve the performance. The qualitative research methodology was adopted. Data was collected from four schools through semi-structured interviews and document analysis. Data was analysed from the perspective of the General System Theory. The results of the study show that performance in Biology 5090 was affected by factors such as human, phusical, information, financial resources, and the transformation processes. The study also suggests ways of improving the performance. These includes: in-service training, development of resource centres and school cluster development.

Keywords: Framework, Science classroom, Teacher practice, teaching difficulties

\section{Introduction}

The education in Lesotho is modelled on the British education system following the colonial model which is the Cambridge Overseas School Certificate (COSC), (Ambrose, 2008). Ambrose (2008) further explains that Lesotho changed to COSC in 1961 moving away from the Joint Matriculation Board (JMB) of the University of South Africa. In COSC learners should take the minimum of six subjects and ought to pass five subjects including English language to secure the School Certificate (SC). Biology 5090 is one of the science subjects in COSC.

Of all the science subjects offered in Lesotho, Biology 5090 performance has been below average since 2006 to 2012. Data collected at Examination Council of Lesotho (ECOL) showed that it was only in 2008 and 2012 whereby Biology 5090 performance was above 50\%. Table 1 shows performance in Biology 5090 from 2006 to 2012.

Table 1. Biology 5090 performance in Lesotho from 2006 to 2012 in percentages (\%).

\begin{tabular}{|c|c|c|c|c|c|c|c|c|c|}
\hline Years & \multicolumn{9}{|c|}{ Grade } \\
\hline & A1 & A2 & B3 & B4 & C5 & C6 & D7 & E8 & U9 \\
\hline 2006 & 0.117 & 0.517 & 3.337 & 2.35 & 2.444 & 8.202 & 11.51 & 14.56 & 56.96 \\
\hline 2007 & 0.496 & 1.496 & 4.496 & 2.98 & 3.111 & 8.967 & 12.99 & 15.00 & 50.87 \\
\hline 2008 & 0.153 & 0.816 & 3.978 & 2.983 & 3.57 & 10.60 & 13.41 & 17.47 & 47.00 \\
\hline 2009 & 0.098 & 0.933 & 3.364 & 2.062 & 2.922 & 7.465 & 12.4 & 15.42 & 55.32 \\
\hline 2010 & 0.220 & 0.93 & 3.54 & 1.91 & 2.747 & 7.324 & 11.73 & 16.19 & 55.48 \\
\hline 2011 & 0.278 & 0.616 & 2.487 & 1.452 & 1.810 & 6.169 & 10.78 & 16.41 & 59.98 \\
\hline 22012 & 0.525 & 1.111 & 4.202 & 2.343 & 3.464 & 10.65 & 14.30 & 19.25 & 44.14 \\
\hline
\end{tabular}

(ECOL 2011, 2012)

Therefore, the study intends to find out factors affecting Biology 5090 performance at the selected high schools in Lesotho and ways of improving Biology 5090 performance. 


\section{Literature Review}

Jackson (2009) conducted the study investigating factors contributing to poor performance of grade 12 (COSC) learners in Lesotho. She found that poor academic performance of learners in Lesotho is attributed to various factors including educators. Tracy (2002) argues that poor performance has caused many learners to lose faith in educators. They feel that their educators are prejudiced against them and care very little either about individual learner or their teaching. Much of the problem, according to Calitz, Fulgestad and Lillejord (2002) derives from the treatment the learners receive from educators and unintended consequences of the school organization and practice. According to Jackson (2009), poor performance of COSC learners in Lesotho can be inter alia, attributed to the following: lack of parental involvement, an inappropriate curriculum, poor school management, a non-welcoming school climate and shortage of educational facilities and resources, second language as a medium of instruction, fear of external examinations, inadequate qualified educators, lack of discipline and poor school attendance by both the educators and learners.

Akiri and Nkechi (2009) are of the opinion that ineffectiveness of teachers in classroom interaction with the learners could be responsible for the observed poor performance of learners and the widely acclaimed fallen standard of education. Poor academic performance of learners can be linked to poor teachers' performance in terms of accomplishing the teaching task, negative attitude to work and poor teaching habits which have attributed to poor motivation (Akiri \& Nkechi 2009). However, in most schools in Lesotho, ineffective teaching is due to conditions such as lack of resources facilitating teaching and learning. That resulted into negative influence on the instructional quality in schools, translated into poor academic performance, attitude and values. The ways learners learn affect their academic performance

Most learners perform below average due to lack of motivation. They are neither motivated to learn nor do they do what they are expected to do. Several researchers have suggested that only motivation directly effects academic achievement; all factors affect achievement only through the effect of motivation (Tucker et al. 2007). However, it is not easy to understand what motivates learners. Numerous studies have been conducted on this topic, which has led to the development of several theories of motivation.

\section{Theoretical Framework}

This research employed the General System Theory (GST) as the theoretical framework for this study. Higgs and Smith (2008) define system theory as a general science of organization and wholeness; it is also regarded as a philosophy that claims that life is a system of which we are a part. The key assumptions in system theory are that; everything including human being is a system of some sort (Higgs \& Smith 2008), and all systems are purposeful and goal directed. In order to achieve goals of the system, all parts of a system should work in harmony with one another and their environment.

The General System Theory (GST) was originally developed by a Biologist Ludwing Von Bertalnffy in (1928). His assumptions pertained primarily to the study of living organisms, machines, galaxies and organizations. He postulated that parts of a system do not work in isolation; they work within a system. His postulation countered a popular scientific view that a system could be understood first by breaking it down into its components so that each component could be studied and analyzed as an independent entity. And that the components could be added in a linear fashion to describe the totality of a system.

Bertalnffy (1968, p.38) defines a system as 'sets of elements standing in interrelation'. Systems can either be closed or opened. The school is the example of an open social system in which two or more persons work together in a coordinated manner to attain common goals (Norlin 2009). All schools are open systems, though the degree of interaction with their environment may vary. The school is a system with the following components, environment, inputs, transformation process, out-puts and feedback. The open system is that type of a system that receives inputs from the environment and releases the outputs to the environment. Any change in the environment can profoundly impact on the open system. Parts of the system interact together for the school system to succeed, or help to locate the source of the problem and as a result find the solution.

This theory has been adopted in this study because the school is an example of the social open system with goals to achieve. One of the major goals of the school is to produce good results. But if parts of the system (school) do not work together as expected, set goals would not be achieved as expected. That is, if the management, parents, teachers, and learners do not work together, obtaining good results could be impossible. With regard to this study, all parts of the school as a system could affect Biology 5090 performance negatively if there can be discrepancies between them. Knowing something about one part of the system helps us to know something about another part (Lunenburg 2010). This implies that, learners, Biology teachers, the management and parents can affect Biology 5090 performance negatively should 
there be some discrepancies

\section{Methodology}

The qualitative interactive case study was adopted for this study. The researcher required face to face interaction with the participants at their natural setting for better understanding, and therefore case study method was found to be suitable. For the selection of participants, the researcher employed purposive sampling. Purposive sampling is based on the assumption that the investigator wants to discover, understand, and gain some insight and therefore must select a sample from which most can be learned (Merriam 2009). The participant's selection was based on the purpose that they could provide information required as their schools had been performing below average in most years from 2006 to 2012 in Biology 5090. Patton (2009, p.128) explains that 'purposeful sampling focus on selecting information- rich cases whose study will illuminate the questions under study'. Four schools whose performance had been below average were selected and given fictitious names for ethical considerations and teachers participating in this study. Schools selected were Popanyane high school, Moreneng high School, Motitseng high school, and Machache high School. These schools were identified easily using the data from the Examinations Council of Lesotho (ECOL) indicating the performances of all schools doing Biology 5090 from 2006 to 2012. One Biology teacher per school participated in this study.

Tables provided below indicate the performance of schools selected for sampling from 2006 to 2012. A1 to C6 show the alphabetical GCE grade awarded while D7 and E8 are ordinary level pass and U9 is ungraded or fail.

Table 2. Popayane High School, Biology 5090 Performance from 2006 to 2012

\begin{tabular}{|c|c|c|c|c|c|c|c|c|c|c|}
\hline \multirow[t]{2}{*}{ Years } & \multicolumn{9}{|c|}{ Grades } & \multirow{2}{*}{$\begin{array}{l}\text { Total no of learners who } \\
\text { sat for } 5090 \text { exam }\end{array}$} \\
\hline & A1 & $\mathrm{A} 2$ & B3 & B4 & C5 & C6 & D7 & E8 & U9 & \\
\hline 2006 & 0 & 0 & 0 & 0 & 0 & 0 & 0 & 0 & 5 & 5 \\
\hline 2007 & 0 & 0 & 1 & 0 & 0 & 0 & 0 & 0 & 3 & 4 \\
\hline 2008 & 0 & 0 & 0 & 0 & 0 & 1 & 0 & 1 & 5 & 7 \\
\hline 2009 & 0 & 0 & 0 & 0 & 0 & 0 & 0 & 2 & 7 & 9 \\
\hline 2010 & 0 & 0 & 0 & 0 & 0 & 1 & 1 & 0 & 12 & 14 \\
\hline 2011 & 0 & 0 & 1 & 1 & 0 & 5 & 2 & 2 & 3 & 14 \\
\hline 2012 & 0 & 0 & 0 & 1 & 0 & 1 & 4 & 7 & 18 & 31 \\
\hline
\end{tabular}

(ECOL 2011, 2012)

Table 3. Moreneng High School, Biology 5090 performance from 2006 to 2012

\begin{tabular}{|c|c|c|c|c|c|c|c|c|c|c|}
\hline Years & \multicolumn{9}{|c|}{ Grades } & \multirow{2}{*}{$\begin{array}{l}\text { Total no of learners who } \\
\text { sat for } 5090 \text { exam }\end{array}$} \\
\hline & A1 & $\mathrm{A} 2$ & B3 & B4 & $\mathrm{C5}$ & C6 & D7 & E8 & U9 & \\
\hline 2006 & 0 & 0 & 1 & 0 & 2 & 4 & 6 & 12 & 26 & 45 \\
\hline 2007 & 0 & 0 & 0 & 0 & 2 & 2 & 3 & 4 & 16 & 25 \\
\hline 2008 & 0 & 0 & 0 & 0 & 1 & 1 & 3 & 11 & 14 & 30 \\
\hline 2009 & 0 & 0 & 0 & 0 & 0 & 3 & 2 & 8 & 26 & 39 \\
\hline 2010 & 0 & 0 & 1 & 0 & 0 & 4 & 4 & 4 & 19 & 32 \\
\hline 2011 & 0 & 0 & 0 & 0 & 0 & 4 & 6 & 9 & 14 & 33 \\
\hline 2012 & 0 & 0 & 6 & 2 & 0 & 5 & 7 & 15 & 21 & 56 \\
\hline
\end{tabular}

(ECOL 2011, 2012)

Table 4. Motsitseng High School, Biology 5090 Performance from 2006 to 2012

\begin{tabular}{|c|c|c|c|c|c|c|c|c|c|c|}
\hline Years & \multicolumn{9}{|c|}{ Grades } & \multirow{2}{*}{$\begin{array}{l}\text { Total no of learners who } \\
\text { sat for } 5090 \text { exam }\end{array}$} \\
\hline & A1 & $\mathrm{A} 2$ & B3 & B4 & $\mathrm{C5}$ & C6 & D7 & E8 & U9 & \\
\hline 2006 & 0 & 0 & 2 & 3 & 1 & 6 & 8 & 4 & 27 & 50 \\
\hline 2007 & 0 & 0 & 0 & 0 & 0 & 3 & 4 & 2 & 25 & 34 \\
\hline 2008 & 0 & 0 & 3 & 3 & 0 & 2 & 6 & 7 & 34 & 55 \\
\hline 2009 & 0 & 0 & 1 & 1 & 0 & 0 & 2 & 3 & 32 & 39 \\
\hline 2010 & 0 & 0 & 1 & 0 & 2 & 3 & 3 & 7 & 5 & 19 \\
\hline 2011 & 0 & 1 & 0 & 0 & 1 & 1 & 2 & 8 & 14 & 27 \\
\hline 2012 & 0 & 0 & 0 & 0 & 0 & 2 & 2 & 2 & 9 & 15 \\
\hline
\end{tabular}

(ECOL 2011, 2012) 
Table 5. Machache High School, Biology 5090 Performance from 2006 to 2012

\begin{tabular}{|c|c|c|c|c|c|c|c|c|c|c|}
\hline \multirow[t]{2}{*}{ Years } & \multicolumn{9}{|c|}{ Grades } & \multirow{2}{*}{$\begin{array}{c}\text { Total no of learners who } \\
\text { sat for } 5090 \text { exam }\end{array}$} \\
\hline & A1 & $\mathrm{A} 2$ & B3 & B4 & $\mathrm{C} 5$ & $\mathrm{C} 6$ & D7 & E8 & U9 & \\
\hline 2006 & 0 & 0 & 0 & 0 & 0 & 0 & 0 & 5 & 21 & 25 \\
\hline 2007 & 0 & 0 & 1 & 1 & 1 & 1 & 2 & 10 & 6 & 22 \\
\hline 2008 & 0 & 0 & 0 & 2 & 2 & 1 & 6 & 5 & 5 & 21 \\
\hline 2009 & 0 & 0 & 2 & 0 & 0 & 3 & 9 & 3 & 15 & 32 \\
\hline 2010 & 0 & 0 & 1 & 0 & 3 & 2 & 5 & 5 & 7 & 23 \\
\hline 2011 & 0 & 0 & 0 & 1 & 0 & 0 & 3 & 10 & 14 & 28 \\
\hline 2012 & 0 & 0 & 1 & 1 & 2 & 6 & 9 & 14 & 20 & 53 \\
\hline
\end{tabular}

(ECOL 2011, 2012

The data for the present research was collected through interviews and document analysis. Semi-structured interviews were used since probing participants was crucial. These methods were used simultaneously because multimethod strategy enhances the credibility of the study. The data collected was analyzed with the aid of qualitative content analysis whereby categories and characteristics were identified. The findings of the study were provided as descriptively as possible.

\section{Results and Discussion}

The table below captures the data analysis scheme which was used for this paper.

Table 6: Data analysis scheme

\begin{tabular}{|c|c|}
\hline $\begin{array}{l}\text { Factors affecting Biology } 5090 \text { performance } \\
\text { (inputs and the transformation process) }\end{array}$ & Examples \\
\hline A. Human resources & $\begin{array}{l}\text { - Teachers and teacher quality } \\
\text { - Learners } \\
\text { - Parents }\end{array}$ \\
\hline B. Physical resources & $\begin{array}{l}\text { - Lack of a Biology laboratory } \\
\text { - Lack of a library }\end{array}$ \\
\hline C. Information resources & $\begin{array}{l}\text { - English as a medium of instructions } \\
\text { - Lack of Biology textbooks for learners and for teachers } \\
\text { - Lengthy syllabus. } \\
\text { - Lack of tests and internal exam question papers and their } \\
\text { marks and the COSC results analysis developed at schools. }\end{array}$ \\
\hline D. Financial resource & Lack of funds to buy resources \\
\hline $\begin{array}{l}\text { E. The transformation process (methods of } \\
\text { teaching and assessing Biology 5090). }\end{array}$ & $\begin{array}{l}\text { Methods teaching } \\
\text { - Discovery } \\
\text { - Group discussion } \\
\text { - Demonstration } \\
\text { - Lecturing } \\
\text { - Involving students in research } \\
\text { Methods of assessment } \\
\text { - Question and answer method } \\
\text { - Quiz } \\
\text { - Giving students tests } \\
\text { - Class work } \\
\text { - Assignment } \\
\text { - Drilling using past question papers }\end{array}$ \\
\hline
\end{tabular}

\subsection{Human resources}

Human resources are inputs to the system. They include: teachers, learners, and parents. In order for the school to produce good results, parts of the system should work in harmony with one another (Lunenburg 2010). Failure to work as 
expected, inputs can to be factors affecting learners' performance in Biology 5090.

\subsubsection{The effect of teachers and teacher quality on learners' performance}

The study uncovered that teacher quality is one of the factors affecting Biology 5090 performance negatively in Lesotho. The suitable qualification in teaching Biology 5090 is Bachelor of Science in Education (BSC ED) with majors in Biology and any Science subject. However, in most schools in Lesotho, Biology is taught by non-certificated teachers. These are those who did not take education courses. This indeed affected Biology 5090 performance negatively because those teachers lacked methods of teaching. Maagan (2007) supports this by saying that learners taught by trained Biology teachers perform better than those taught by teachers who did not take education courses. Jackson (2009) indicates that there is high shortage of relevant and qualified teachers in areas of Mathematics and science in Lesotho high schools. This indeed affects performance negatively. There is high rate of absenteeism among teachers and lack of commitment. Most teachers do not attend Biology lessons as expected and this, of course, affect Biology 5090 performance negatively as they fail to finish the syllabus on time, and do not have enough time for learners.

\subsubsection{The effects of learners on Biology 5090 performance}

Learners are seen to play a major role in affecting Biology 5090 performance in Lesotho high schools. They ignore the work assigned to them and they do not show any interest in their school work. Jackson (2009) has the opinion that learners affect performance negatively. He argues:

Lack of learners discipline affects performance badly. Some learners are ill disciplined, uncontrollable, and difficult to work with in class. Such learners deliberately ignore instructions from teachers, leave the class during lessons, come to school late or disappear before school close.

To add on this, learners have phobia in Biology as it involves Mathematics especially in papers 3 and 6 . They fail to plot the graph when co-ordinates are given even to answer questions when graphs are drawn for them. And this leads to low performance in Biology. Learners' background affects Biology 5090 performance too. Learners with poor scores in integrated science at junior level tend to perform badly in Biology as they do not show any kind of motivation. Uzoechi (2009) supports this by saying that learners' knowledge backgrounds in Biology have significant effect on learners' performance. A learner, therefore, with poor background is likely to have poor performance in Biology.

\subsubsection{The effect of parents on Biology 5090 performance}

In order for the school to achieve good results, people involved including parents should work together (Norlin 2009). The major role of parents in education is to pay schools fees on time and to buy books for their children. In Lesotho, however, most parents do not play this role as expected. And this affects Biology 5090 performance negatively as some learners are expelled from school for fees and come after a longer period of time. Nzelum (2010) explains that parental involvement in children's education has a definite impact on learners' level of academic success. Rouse and Barrow (2006) have observed that economically disadvantaged parents are less able to afford the cost of education of their children and learners do not do their work to their fullest potential because sometimes they are expelled from school for fees. During their absence, the learning and teaching still occur as normal and this affects performance as some learners who would get better grades would not at the end of the course.

\subsection{Physical resources}

For the school to operate as expected there must be enough physical resources enabling the transformation process to occur easily. Physical resources include the equipped science laboratory and the library. Biology is learned better through involving learners and this is achieved only by letting learners to carry out practicals on their own. In Lesotho, most schools do not have equipped science laboratories and this affects Biology 5090 performance negatively. Jackson (2009) supports this by saying that many of the laboratories in some schools are inoperative because of lack of equipment to carry out practical exercises. These include lack of gas, running water, electricity to name but few. In support of this, Machobane (2000) points out that more schools in Lesotho are talk chalk and they do not have proper resources hence teaching and learning becomes difficult. Therefore, lack of resources such as equipped laboratories contributs to poor performance since Biology is learned better through hands on activities. Words alone are insufficient to explain concepts to learners to capture and retain their attention and interests. Hands on activities facilitate the understanding of scientific 
concepts.

\subsection{The information resources}

The information resources are considered to be inputs to the system. Information resources include knowledge of which language is a part, syllabus, curricula and data. Information resources due affect Biology 5090 performance negatively.

\subsubsection{Language as a medium of instruction}

Language is not only a tool for communication but it is also a resource for creative thought, a framework for understanding the world, a key to new knowledge, human history and a source of pleasure and inspiration (Kern 2008). In Lesotho, English is used as a medium of instruction for all subjects except in teaching Sesotho. But it imposes many problems leading to low performance in Biology 5090. Learners fail to understand concepts presented to them in English and in trying to discuss them, this leads to misconceptions hence low performance. They even fail to understand concepts presented to them in Biology textbooks. Seotsanyane (2002) supports this by saying that 'most learners are not fluent in English and this affect their Biology 5090 performance negatively as they cannot express themselves fully when answering the questions'.

\subsubsection{The lengthly syllabus and use of Biology textbooks}

The Biology curriculum is overloaded with facts and the syllabus is very long (Dillion 2008). The other information resource affecting Biology 5090 performance is the lengthy syllabus which is difficult to cover. In order to finish the Biology 5090 syllabus, teachers ought to have extra lessons during weekends or during winter breaks. Failure to do this results into poor performance as it is difficult to cover the whole syllabus. To add on this, there is a shortage of textbooks for learners. Parents are not doing their responsibilities as expected and indeed this affects Biology 5090 performance negatively in Lesotho. Text books play a very important role in the learning of Biology since learners have the chance to extend their learning at home. The absence of textbooks affects Biology 5090 performance negatively since learners depend on notes alone. The notes themselves are never adequate.

\subsubsection{Lack of data (Records)}

There are various importances for keeping the school records. Silverman (2010) explains that records reveal what people did and what they value. They are used to gain knowledge and insight on behavior of the people involved. School records tell the history of the school and are useful historical sources (Durosaro 2007). Records further provide the information needed on ex-learners either for institutions or for research purposes. For this study, records to be collected at schools selected included past question papers for tests and internal examinations, marks obtained from 2006 to 2012 in Biology 5090, and the COSC analysis developed at schools from 2006 to 2012. However, most schools did not provide the researcher with the records requested and the analysis was based on the available data. Tests and internal question papers collected at some schools were of standard. Records indicated that learners were not tested as frequently as expected though testing is very important. Lack of testing was found to be another factor affecting Biology 5090 negatively.

\subsection{Financial resources}

Financial resources refer to the capital the school uses to finance both the ongoing and long-term operations (Lunenburg 2010). Lack of financial support at any school affects performance negatively. In order for the transformation process to occur as expected, there must be aids facilitating the process of teaching and learning. Learners understand better if teaching aids are used. Most schools that take part in this study do not have the financial support. This affects Biology 5090 performance negatively as it is difficult to buy teaching aids. At the situations whereby schools do not have enough grants it is difficult for the schools to hire qualified teachers due to lack of funds. Indeed lack of capital affected Biology 5090 performance negatively in Lesotho. Jackson (2009) supports this by explaining that words alone are insufficient to explain concepts to learners to capture and retain their attention and interests. Educational resources prevent the blind memorization of words without any association to definite object. Akiri and Nkechi (2009) argue that ineffective teaching is due to conditions such as lack of recourses facilitating teaching, and this results into negative influence on the 
instructional quality in schools. This may translate to poor academic performance, attitude and values.

\subsection{The transformation process (teaching and assessment strategies in Biology)}

The way Biology is taught and assessed could be regarded as one of the factors affecting Biology 5090 performance. Biology is taught differently in different schools due to lack of teaching aids. The teaching style plays a very important role in the academic success of learners. Lack of knowledge about the teaching style affects academic performance of learners negatively (Araoye 2010). In teaching Biology, teachers used discovery, group discussion, demonstration, lecturing, research and demonstration. They explained that they could not use experimentation due to lack of equipped laboratories at their schools and indeed that affected Biology 5090 negatively as learners were not exposed to practicals. Lecturing according to Wood (2009) is a traditional method that failed the majority of learners who view Biology as a collection of disconnected facts with little relevance to their lives. This method of teaching contributes a lot in low performance in Biology 5090 as teachers have the fully responsibility in presenting facts and principles while learners are regarded as empty vessels without ideas (Thomas 2013). As for other methods mentioned above, except for lecturing, learners contributes in learning as they are involved in the process.

Assessment is used to find out if learning has occurred. Biology teachers should choose methods of assessment which enable them to ascertain the status of learners in the learning process hence find ways of helping them. Methods of assessment used were question and answer method, quiz, tests, assignment, and drilling using the past question papers. Drilling was used towards writing the external examinations as a preparation for the final examination (Respondent). Question and answer method was used during the lesson in order to find out if learners were still on the right tract. Tests and quizzes were not given frequently by most teachers in order to check the learning progress as data collected indicated. James (2000) has the opinion that frequent testing is very important as it provides information about learners' progress and it helps the teacher to diagnose specific learners' strength and weakness. This can lead to improved instruction for learners but in Lesotho this is not the case.

\subsection{Ways of improving Biology 5090 in Lesotho high schools}

According to system theory, negative feedback implies that there are discrepancies in the parts of the system. And negative feedback can be used to correct deficiencies in the system. Poor performance in Biology 5090 calls for corrections in all parties taking part in the school as a system. Corrections can either be on the transportation process, inputs, or both (Lunenberg 2010). Biology teachers suggested various strategies that they assumed would bring positive changes in Biology 5090 if employed. These included teamwork, development of resource centres, in-service training, and improvising, devising methods of teaching, reading about the latest Biology discoveries, remedial lessons, and giving learners more work.

In order to improve Biology 5090 performance teachers thought of teamwork and development of school clusters whereby teachers could work together to solve problems they experienced at their various schools. Teamwork involves teachers planning together for a certain group of learners and helping one another in presenting some topics. Yates (2000) explains that if the transformation process fails to go as planned due to failure of the teacher to present the content, teachers opt for team teaching. Team teaching enables the transformation process to occur at ease because teachers help one another. A school cluster is a group of schools working together to achieve a common goal. It involves teachers from different schools working together and encouraging one another to find ways of improving their teaching and skills for better learning (Nwagbo 2008). Through teamwork and development of school clusters Biology 5090 performance could change to the better as teachers would work together to achieve the common goal.

Biology 5090 performance could also be improved through the development of resource centres. Resource centres would help a lot as they could provide help and material resources aiding the process of teaching and learning. Through the development of the resource centres, schools can rent apparatus, charts and even to buy chemicals at small quantities. Biology teachers also thought of giving learners more work and had remedial lessons so as to finish the long syllabus. Methods of teaching Biology at present did not produce better results and these prompted teachers to devise methods of teaching so that a lot of work would be done by the learners instead of them. However, due to lack of equipped laboratories teachers proposed improvisation. Ndirangu (2003) explains that improvisation is the act of creating something in the absence of the ideal tool as a result of lack of funds not having access to the resources needed to perform an experiment. Biology teachers were also advised to read the latest discoveries on Biology and to have inservice training as a way of improving their professional development. This would help a lot in improving Biology 5090 as they would acquire new knowledge through reading and during in-service training. 


\section{Conculsion}

The present study revealed possible factors responsible for the poor performance shown at selected high schools in Lesotho. These included among others: learners, teachers, parents, the management, lack of financial support, lack of equipped libraries, laboratories and Biology textbooks, methods of teaching and assessing Biology 5090. The study also revealed possible strategies suggested by Biology teachers that would bring positive changes in Biology 5090 performance in Lesotho if employed. These included team teaching, development of school clusters and resource centres, improvising, devising methods of teaching and assessing learners, giving learners more work, reading the latest discoveries on Biology, in-service training, and remedial lessons. Avenues for further research could be on the impact of the possible strategies to improve the performance

\section{References}

Akiri, AA \& Nkechi, UM 2009, 'Teachers effectiveness and student's academic performance in republic secondary schools in Delta State', Nigeria, Journal of stud Hom Comm, sci 3(2):107-113.

Ambrose, D 2008, Cambridge Overseas School Certificate: A survey of 40 years of Lesotho Results ... and Comparative High School Performance for the years 2003 -2007, NUL: House of Publication.

Ayaoye, MI 2010, A practical approach to effective teaching of the nervous system using CUE CARDS. A paper presented at STAN Biology panel workshop at Model Girls Secondary Rumeme, Port-Harcourt, State River. $13^{\text {th-17 }}$ April 2010.

Bertalanffy, LV 1968, General System Theory: Foundations, Development, Applications, Braizeller, New York.

Calitz, L, Fulgestad, L \& Lillejord, S 2002, Leadership in Education, London, SAGE.

Dillion, J 2008, A review of the research on practical work in school science, retrieved on 23-08-2013 from http://www.scoreeducation.prg/media/67/review-of-researchpdf.

Durasaro, DC 2007, Management of school records, The crafts of education management DC, Durasaro, S. Oguusaju (ed) llirin, Indemic print media.

Examination Council of Lesotho, Grade Distribution Tubular Reports: Analysis Subjects Grade by Option, 2011 and 2012.

Higgs, P \& Smith, J 2008, Rethinking truth, $2^{\text {nd }}$ edition, Juda, Cape town.

Jackson, MM 2009, An investigation into the factors contributing to the poor performance of grade 12 (COSC) learners in Lesotho, Master's Thesis, University of Zululand.

James, WP 2000, Testing! Testing! What Every Parent Should Know About Tests, Allyn \& Bacon, Boston.

Kern,R,2008, ' Making connections through texts in language teaching', Journal of Education Research, 41(3):367-387

Nwagbo, CR 2008, Practical approach to effective teaching of local and major biotic communities (biomes) to secondary students for sustainable development science teacher association in Nigeria (STAN) Biology panel series 2000.

Lunenburg, FC 2010, 'Schools as open systems', Journal of Schooling, 1(1): 1-5.

Maggan, D 2007, Teaching staff survey in elementary schools (2005/6), Jemsalem: Israel central Bureau of statistics.

Machobane, LB 2000, Police politics and development, recent history of education policy and development in Lesotho, retrieved on 0404-2013 from www.education, gv.ls.

Merriam, SB 2009, Qualitative Research: A guide to design and implementation, San Francisco: Johnweley \& Sons.

Ndirangu, M 2003, Science teaching alive, Improvisation in science teaching, retrieved on 17-08-2013 from www.ehow.com/infor8169958-practices-science-improvisation-school.html

Norlin, JM 2009, Human behavior and the social environment: Social system theory, Upper Saddle River, NJ: Allyinad Bacon.

Nzelum, VN 2010, Mechanisms of transmission of information along the neurons: A practical approach to reflex action. A paper presented as STAN Biology panel workshop model of girls secondary schools, Rumeme, Port-Harcourt. River state.

Patton. MQ 2009, Qualitative Research and Evaluation methods, Sage publication.

Rouse, CE \& Barrow, L 2006, 'US elementary and secondary schools: Equalizing opportunities of replacing the status quo?' Journal of the future of children, 16 (25): 99-123.

Seotsanyane, M. 2000, Radical pedagogy, retrieved on 23-02-2013 from http://www.kipedia.org/wiki/english.

Silverman, D 2010, Qualitative Research: Theory, methods and practice, $2^{\text {nd }}$ edition, London: Sage, Mashall, \& Roseman.

Thomas, NO 20013, 'The effect of teacher preparation on students' academic achievement in SS2 Biology practicals, Journal of education and practice, 4(8):1-14.

Tracy, E 2002, The students guide to exam success, Philadelphia: Open University Press.

Tucker, CM, Zyco, RA \& Herman, KC 2007, Teacher and child Variables as predictors of academic enjoyment among low-income African American Children, psychology in the schools, 39(4):477-488.

Uzoechi, BC 2009, Techniques for preserving biological specimen for effective conduct of practical Biology, STAN Biology panel series, Nwagbo CR, Nzewi UM and Ajewole (eds) Nukka.

Wood, WB 2009, Innovations in Teaching Undergraduate Biology and Why We Need them, Master's Thesis, University of Colorado 